\title{
Benefits from plant resistance in reducing reliance on fungicides in cereal disease management
}

\author{
S.L.H. Viljanen-Rollinson, M.V. Marroni and R.C. Butler \\ New Zealand Institute for Plant E Food Research Limited, Private Bag 4704, \\ Christchurch 8140, New Zealand \\ Corresponding author: suvi.viljanen@plantandfood.co.nz
}

\begin{abstract}
Two field trials, autumn- and spring-sown, with seven fungicide treatments and three wheat cultivars with different levels of resistance to Puccinia striiformis, the cause of stripe rust, were carried out at Lincoln during the 2009-2010 growing season to assess the value of utilising disease resistance within an integrated wheat disease management strategy. The development of stripe rust was monitored during the season. The resistant cultivar CFR02-452 was free of stripe rust in all treatments, including the no fungicide treatment. There was more disease in the autumn-sown trial than in the spring-sown trial. The moderately resistant cultivar Torlesse had less stripe rust than the susceptible cultivar Claire in both trials and negligible disease in the spring-sown trial. In cultivar Claire for both trials, two fungicide applications that started before disease was present provided disease control that was similar to four applications, but fungicide applications that commenced once the disease had established provided little control of stripe rust.
\end{abstract}

Keywords wheat, stripe rust, Puccinia striiformis, AUDPC, resistance.

\section{INTRODUCTION}

Stripe rust, caused by Puccinia striiformis f.sp. tritici, is a serious disease of wheat in New Zealand, and is mainly controlled by application of fungicides or by planting resistant cultivars. Chemical control of stripe rust contributes to production costs, and importantly, changing market standards increasingly require growers to reduce fungicide use to minimise impacts on human and environmental health. The efficacy of fungicides depends on cultivar resistance, the crop growth stage, and disease pressure and severity at the time of application.

Resistant wheat cultivars have been successfully deployed in New Zealand, but stripe rust levels in many cultivars have increased due to virulence developing to several of the resistance genes contained in these cultivars.
Over 30 different pathotypes of P. striiformis f. sp. tritici have been recorded in New Zealand (M.G. Cromey, Plant \& Food Research, pers. comm.). Resistance in cultivars may be vertical (major gene), which can reduce the disease intensity to zero if there is no corresponding virulence in the pathogen population, or horizontal (minor gene, rate-reducing, partial or field) resistance, which does not prevent disease, but reduces its intensity (Madden et al. 2007). A cultivar may have both vertical and horizontal resistance. Resistance to stripe rust in wheat cultivars is sometimes referred to as all-stage resistance, which is expressed at all stages of plant growth (seedling and adult plant) or as adult plant resistance, which is expressed at later stages of plant growth (Line \& Chen 1995). Resistance to a pathogen is considered to 
be durable when a cultivar possessing it remains largely unaffected when widely cultivated over an extended period of time (Johnson 1981). Around 40 resistance genes have been reported to confer stripe rust resistance in wheat and have been used in breeding programmes (McIntosh et al. 1995). Durable stripe rust resistance has largely been of the adult plant type.

As part of a research programme seeking ways to reduce reliance on fungicides in New Zealand's arable, vegetable and horticultural crop production systems, this study sought to determine the value of genetic disease resistance and targeted fungicide applications in reducing stripe rust in wheat cultivars with various levels of resistance. This report presents data on disease intensity from two field trials in a single season. It forms part of a wider study to identify levels of partial resistance in new cereal cultivars that would be useful in reducing reliance on fungicides against foliar diseases.

\section{MATERIALS AND METHODS}

Three wheat cultivars, CFR02-452 (an advanced breeding line, resistant), 'Torlesse' (moderately resistant) and 'Claire' (susceptible to the pathotype 234E139A, Yr17+), were each treated with seven different fungicide treatments in which the number and timing of applications varied in relation to the appearance of stripe rust in the trials (Table 1). The treatments were applied in an autumn- (18 April 2009) and spring-sown (24 August 2009) field trial at Lincoln, Canterbury, New Zealand. Each fungicide application was a mixture of epoxiconazole (125 g ai/ha, Opus $\left.{ }^{\circledR}\right)$ and azoxystrobin (250 g ai/ ha, Amistar $\left.{ }^{\circledR}\right)$. It was assumed that this fungicide mix would provide protection against stripe rust for approximately 4 weeks. Both trials had three replicates of the 21 treatment combinations (three cultivars and seven fungicide treatments), laid out in a Latinized resolvable row-column design, of seven by nine plots. Each set of seven by three plots formed a replicate. Plots were $1.7 \mathrm{~m}$ wide and $1.8 \mathrm{~m}$ long. For the autumnsown trial, the first fungicide application (for A1, A2 and A3 treatments) was applied to the incorrect plots. Thus, the treatments had to be re-allocated to plots, taking into account the cultivars (correctly sown), and the incorrect first fungicide application.

Plants were inoculated with the pathotype 234E139A, $Y r 17+$, which is virulent on host genes Yr2, Yr3, Yr4, Yr7, Yr9 and Yr17, on 9 September 2009 for the autumn-sown trial, and on 2 November for the spring-sown trial, by planting infected plants in the trial site as described previously (Viljanen-Rollinson et al. 2002).

The first disease assessment was made on 29 September for the autumn trial and on 20 November for the spring trial. Subsequently, ten and eight further assessments respectively were made weekly for each trial. At each assessment date, 10 plants per plot were taken at random and disease was recorded as percentage leaf area affected by stripe rust (percentage severity) for each leaf position on the mainstem.

Mean percentage of stripe rust severity for each leaf, date, cultivar and fungicide treatment was calculated. There was little disease on the flag (F) leaf and on leaf F-6, of Claire and Torlesse in the autumn trial; therefore, formal analyses were carried out on data for leaves F-1 to F-5 only in these instances. Similarly, formal analyses were carried out only on data for Claire for leaves F-1 to F-3 in the spring trial as the disease levels in Torlesse were very low. No disease was found on cultivar CFR02-452 so this cultivar was excluded from analyses. Disease severity was used to calculate area under the disease progress curve (AUDPC) using the formula:

$$
\text { AUDPC }=\sum_{d=0}^{n} \frac{1}{2}\left(y_{i+1}+y_{i}\right)\left(x_{i+1}-x_{i}\right)
$$

where $x_{i}$ is the number of days since inoculation, at assessment $i$, and $y_{i}$ the score at assessment $i$ and $n$ is the number of assessments. AUDPC was analysed with analysis of variance for both trials.

\section{RESULTS}

Overall, disease severity was greater in the autumn-sown trial than the spring-sown trial and the cultivar Claire had more stripe rust than Torlesse. The cultivar CFR02-452 was highly 
Table 1 Descriptions of fungicide treatments, application dates in 2009-2010 and decimal growth stage codes (GS (Zadoks et al. 1974); in parentheses) for autumn- and spring-sown wheat trials.

\begin{tabular}{|c|c|c|}
\hline Description & Autumn trial & Spring trial \\
\hline Nil & No fungicides & No fungicides \\
\hline $\begin{array}{l}\text { A1: first application at inoculation and } \\
\text { three subsequent applications at } 4 \text {-week } \\
\text { intervals }\end{array}$ & $\begin{array}{l}29 / 9(31-32), 30 / 10(37) \\
27 / 11(59), 21 / 12(71)\end{array}$ & $\begin{array}{l}30 / 10(32), 30 / 11(37-39), \\
21 / 12(69), 15 / 1(+71)\end{array}$ \\
\hline $\begin{array}{l}\text { A2: first application at inoculation and } \\
\text { second } 4 \text { weeks later }\end{array}$ & $29 / 9(31-32), 30 / 10(37)$ & $30 / 10(32), 30 / 11(37-39)$ \\
\hline $\begin{array}{l}\text { A3: first application at inoculation and } \\
\text { second } 8 \text { weeks later }\end{array}$ & $29 / 9(31-32), 27 / 11(59)$ & - \\
\hline $\begin{array}{l}\text { A4: first application at inoculation and } \\
\text { second } 4 \text { weeks later }\end{array}$ & - & $12 / 11(37), 7 / 12(51)$ \\
\hline $\begin{array}{l}\text { B1: first application after disease was first } \\
\text { present and second } 4 \text { weeks later }\end{array}$ & 23/10 (32), 23/11 (55) & 23/11(37), 21/12 (69) \\
\hline $\begin{array}{l}\text { B2: first application } 2 \text { weeks after disease } \\
\text { was first present and second } 4 \text { weeks later }\end{array}$ & $5 / 11(39), 3 / 12(69)$ & $7 / 12(51), 31 / 12(69)$ \\
\hline $\begin{array}{l}\text { B3: first application } 4 \text { weeks after disease } \\
\text { was first present and second } 4 \text { weeks later }\end{array}$ & 20/11 (55), 14/12 (71) & $14 / 12(59), 10 / 1(+71)$ \\
\hline
\end{tabular}

resistant, showing no stripe rust symptoms in either trial, even in the nil-fungicide plots. During the 2009-2010 growing season, stripe rust severity on flag leaves was unusually low in both the autumn- and spring-sown trials.

\section{Autumn-sown trial}

In the Nil fungicide plots of the autumn-sown trial Torlesse showed much lower stripe rust intensity, as represented by mean AUDPC values, than Claire (Table 2), reflecting the lower susceptibility of Torlesse to the $P$. striiformis pathotype used to inoculate the trial. Treatment with four fungicide applications 4 weeks apart (A1) reduced stripe rust in both Claire and Torlesse to a negligible level and thus achieved similarly low disease intensity to that in the highly resistant CFR02-452. All of the treatments that received the first application of fungicide after stripe rust was already present (B treatments) had greater disease intensity than those with the first application before the disease was present (A treatments) in both Torlesse and Claire. The earlier the applications, the less stripe rust that developed in both cultivars. Fungicide treatment
A2, in which the first application coincided with

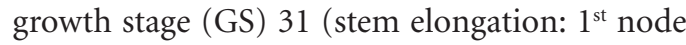
detectable) and second application with GS 37 (Flag leaf just visible), provided as good control of stripe rust as four applications (A1).

Mean AUDPC generally increased with leaf age $(\mathrm{P}<0.001)$, increasing from leaf $\mathrm{F}-1$ to leaves F-3 and F-4, but declining slightly to leaf F-5 (Table 2). Mean AUDPC on F-1 was low for treatments B2 and B3 but increased to similar levels to the Nil treatment from leaf F-2 onwards. Leaf F-3 had greatest levels of stripe rust. Treatment B1 (first application after disease was first present and second application 4 weeks later) protected the top three leaves (F-1, F-2 and F-3) of cultivars Torlesse and Claire more than treatments B2 and B3 (Table 2). The mean maximum disease severity varied from 2 to $35 \%$ in Torlesse and from 7 to $64 \%$ in Claire (data not shown).

\section{Spring-sown trial}

In the spring-sown trial Torlesse showed lower disease intensity than Claire to an even greater extent than in the autumn-sown trial. The 
Table 2 Mean area under the disease progress curve (AUDPC) values for cultivars 'Torlesse' and 'Claire' for different leaves ( $\mathrm{F}=$ flag leaf) for the six fungicides and the nil treatment in the autumn-sown trial. Treatment A1 had negligible stripe rust on all leaves and was not included in the analysis.

\begin{tabular}{|c|c|c|c|c|c|c|c|c|c|c|c|c|}
\hline \multirow[b]{2}{*}{ Treatment } & \multicolumn{5}{|c|}{ Torlesse } & \multicolumn{7}{|c|}{ Claire } \\
\hline & F-1 & F-2 & F-3 & F-4 & F-5 & Mean & F-1 & F-2 & $\mathrm{F}-3$ & F-4 & F-5 & Mean \\
\hline Nil & 88 & 225 & 406 & 443 & 419 & 316 & 1319 & 1858 & 2555 & 1123 & 997 & 1570 \\
\hline A1 & - & - & - & - & - & - & - & - & - & - & - & - \\
\hline A2 & 0 & 62 & 130 & 252 & 189 & 127 & 93 & 216 & 215 & 212 & 31 & 153 \\
\hline A3 & 103 & 135 & 87 & 117 & 0 & 88 & 609 & 749 & 938 & 202 & 41 & 508 \\
\hline B1 & 8 & 36 & 176 & 307 & 328 & 171 & 187 & 667 & 1235 & 1145 & 834 & 814 \\
\hline B2 & 62 & 167 & 438 & 355 & 254 & 255 & 717 & 1373 & 2130 & 1178 & 775 & 1235 \\
\hline B3 & 52 & 293 & 475 & 391 & 447 & 332 & 904 & 1419 & 2025 & 1006 & 827 & 1236 \\
\hline
\end{tabular}

${ }^{1} \mathrm{LSD}$ is for comparison between individual leaves only (not for comparing means for all leaves).

Table 3 Mean maximum disease severity (DS, percentage leaf area affected) for cultivars 'Torlesse' and 'Claire', and the mean area under the disease progress curve (AUDPC) values for cultivar 'Claire' for leaves F-1, F-2 and F-3 (F- flag leaf) for six fungicides and the nil treatment in the spring-sown trial. Treatment A2 had negligible stripe rust on all leaves and was not included in the analysis.

\begin{tabular}{|c|c|c|c|c|c|c|}
\hline \multirow[b]{3}{*}{ Treatment } & \multirow[t]{2}{*}{ Torlesse } & \multicolumn{5}{|c|}{ Claire } \\
\hline & & \multicolumn{4}{|c|}{ Mean AUDPC } & \multirow[b]{2}{*}{ Max DS (\%) } \\
\hline & Max DS (\%) & F-1 & F-2 & F-3 & Mean $(F-1, F-2 \& F-3)$ & \\
\hline Nil & 15 & 1640 & 2132 & 1161 & 1644 & 75 \\
\hline A1 & 0 & 39 & 42 & 40 & 40 & 6 \\
\hline A2 & 0 & - & - & - & 0 & 4 \\
\hline A4 & 0 & 0 & 204 & 756 & 320 & 25 \\
\hline B1 & 7 & 0 & 344 & 756 & 367 & 34 \\
\hline B2 & 8 & 258 & 537 & 1060 & 618 & 38 \\
\hline B3 & 15 & 523 & 829 & 1147 & 833 & 32 \\
\hline
\end{tabular}

${ }^{1}$ LSD is for comparison of AUDPC for each leaf; to compare any mean AUDPC (not for mean for all leaves) with zero mean AUDPC, the LSD $(\mathrm{P}=0.05)$ is 229.

response to the fungicide treatments was similar to the autumn-sown trial, with four fungicides (A1) and two early fungicides (A2) reducing stripe rust intensity to a negligible level, in both cultivars. For cultivar Claire, fungicide applications that started before stripe rust was present (A treatments) were more effective than applications that started after disease was present (B treatments).
The maximum disease severities on Torlesse were higher on the Nil and B3 treatments, although for both they were below 15\% during the growing season (Table 3). Little disease was found on treatments $\mathrm{A} 1, \mathrm{~A} 2$ and $\mathrm{A} 4$, while mean severities were below $8 \%$ for the B2 treatment and below $7 \%$ for the $\mathrm{B} 1$ treatment.

Maximum disease severities on Claire were higher on the Nil, B1, B2 and B3 treatments, 
reaching levels of 75, 34, 38 and 32\% respectively during the growing season. Treatments A1 and A2 had the lowest mean maximum disease severities and mean AUDPC for all leaves during the growing season.

\section{DISCUSSION}

Although the season in which the trial was carried out had relatively low stripe rust risk (S. Shorter, Plant \& Food Research, pers. comm.), the highly susceptible cultivar, Claire, required two early or four fungicide applications to achieve as low a disease intensity as the highly resistant cultivar, CFR02-452. Torlesse, the moderately resistant cultivar, required at least two appropriately timed fungicide applications in the autumn-sown trial to achieve the low disease intensity seen on CFR02-452. Disease intensity in Torlesse was very low in the springsown trial. Torlesse has been observed to vary from moderately susceptible in seasons conducive to stripe rust to moderately resistant in less conducive seasons. Stripe rust development in these trials reflected the general expectation that autumn-sown wheat crops suffer greater stripe rust intensity than spring-sown crops. In both the autumn- and spring-sown trials, treatments with fungicide applications that started before disease was present, followed by a second application 4 weeks later, resulted in lower stripe rust intensity than fungicides applied later in the susceptible cultivar Claire. These applications coincided with growth stages GS32 and GS37 in the autumn-sown trial and GS31-32 and GS 39 in the spring-sown trial and provided disease control that was similar to that obtained with four applications. The importance of early fungicide applications to control stripe rust on susceptible cultivars in New Zealand has been reported previously (Viljanen-Rollinson et al. 2006). The top three leaves of wheat plants contribute to approximately $70-75 \%$ of yield (Thomas et el. 1989) and management practices aim to keep these leaves, particularly the flag leaf, free of disease.

During this study, the resistant cultivar CFR02452 was not affected by stripe rust, indicating that, in the absence of virulent pathotypes of P. striiformis, plant resistance is sufficient to control the disease. If the resistance in this cultivar proves to be durable, then it could be grown without the need for fungicides, although caution is required because of the propensity of $P$. striiformis to overcome resistance genes (McIntosh et al. 1995).

The results from this study provide information about the level of fungicide use required in susceptible cultivars to achieve similar disease control to that in highly or partially resistant cultivars. Further analyses of data from these trials will investigate interactions between cultivar susceptibility and fungicides in relation to yield. The information collected from these trials will provide breeders with targets for levels of quantitative resistance required for gene selection in new wheat cultivars. Ultimately, this work will contribute to crop management recommendations that extend the durability of plant resistance to stripe rust. Future work will explore further potential for reduction of fungicide use through application of a single active ingredient per application date, testing cultivars resistant to stripe rust developed as part of the whole research contract, targeting of key growth stages and monitoring seasonal disease risk.

\section{ACKNOWLEDGEMENTS}

Funding for this research was provided by the New Zealand Foundation for Research, Science and Technology through Contract CO6X0810. Cathy Munro sowed and managed the trials. Robert Beresford, Matthew Cromey and Steve Shorter provided valuable advice.

\section{REFERENCES}

Johnson R 1981. Durable resistance: definition of genetic control, and attainment in plant breeding. Phytopathology 71: 567-568.

Line, RF, Chen, XM 1995. Successes in breeding for and managing durable resistance to wheat rusts. Plant Disease 79: 1254-1255.

Madden LV, Hughes G, van den Bosch F 2007. The study of plant disease epidemics. The American Phytopathological Society, St. Paul, Minnesota USA. 421 p. 
McIntosh RA, Wellings CR, Park RF 1995. Wheat Rusts: an Atlas of Resistance Genes. Kluwer Academic Publishers, Dordrecht, The Netherlands. 200 p.

Thomas MR, Cook RJ, King JE 1989. Factors affecting development of Septoria tritici in winter wheat and its effect on yield. Plant Pathology 38(2): 246-257.

Viljanen-Rollinson SLH, Marroni MV, Butler RC 2006. Wheat stripe rust control using fungicides in New Zealand. New Zealand Plant Protection 59: 155-159.
Viljanen-Rollinson SLH, Parkes RA, Armour T, Cromey MG 2002. Fungicide control of stripe rust in wheat: protection or eradication? New Zealand Plant Protection 55: 336-340.

Zadoks JC, Chang TT, Konzak CF 1974. A decimal code for the growth stages of cereals. Weed Research 14: 415-421. 